\title{
Morphological Study of the Structure and Development of Longan Inflorescence
}

\author{
Miki Nakata and Nobuo Sugiyama \\ Graduate School of Agricultural and Life Sciences, Tokyo University, Bunkyo-ku, Tokyo 113-8657, \\ Japan \\ Tanachai Pankasemsuk \\ Faculty of Agriculture, University of Chiang Mai, Chiang Mai 50200, Thailand
}

\begin{abstract}
AdDitional INDEx words. dichasium, Dimocarpus longan, floral induction, inflorescence morphogenesis, monopodial, sympodial, thyrse
\end{abstract}

\begin{abstract}
Aвstract. The structure and developmental patterns of inflorescence of longan (Dimocarpus longan Lour.) were studied microscopically and by the naked eye. In inflorescence of longan, compound dichasia are arranged on three to four orders of monopodial axes without the formation of terminal flowers, indicating that longan inflorescence is pleiothyrse; cymose partial inflorescences are arranged on more than two monopodial axes. Most of the monopodial axes had differentiated by the end of November just before the cool season. The first sign of inflorescence formation was the appearance of bract primordia at apical meristems of the preformed monopodial axes, with lateral axes preceding the main axes. Dichasia were formed in the axils of bract primordia, and the formation of bracts and dichasia continued. Bract appearance can be detected by the naked eye 1 week after microscopically detected bract appearance. Shoots with intermediate characteristics between the inflorescence and the vegetative shoots were formed; dichasia were formed on the lateral axes, but not on the main axes in intermediate shoots. These results suggest that apical meristems on the terminal shoot produce monopodial axes, together with foliage leaf primordia, before floral induction, but produce bract primordia and compound dichasia, which are composed of sympodial axes, after floral induction.
\end{abstract}

Longan, a member of the Sapindaceae family, is a fruit of leading economic importance in Thailand. Flowering is the critical factor determining longan yield (Thunyarpar, 1998). Many attempts have been made to obtain a better understanding of longan flowering, especially in relation to the effects of plant growth regulators; however, there are few studies on the morphological characteristics and development of the longan inflorescence because of its complex structure. Subhadrabandhu and his coworker (Subhadrabandhu, 1990; Yaacob and Subhadrabandhu, 1995) described longan inflorescences as consisting of dichasia, but the pattern of dichasia arrangement in the inflorescence has not been reported. In litchi (Litchi chinensis Sonn.), which belongs to the Sapindaceae, the structure of the inflorescence conforms to pleiothyrsoid composed of dichasia (Robbertse et al., 1995). As for the formation of the inflorescence in longan, Qiu et al. (2001) reported that it can be distinguished when bract primordia become visible on the lateral axes. In litchi, the first sign of inflorescence formation is the broadening and flattening of the shoot apical meristem, followed by the appearance of primary branches at the edge of the shoot apical meristem (K. Ishihata, personal communication; Shukla and Bajpai, 1974). These observations, however, were limited to the shoot apical meristems and nearby regions, and the overall changes in the inflorescence have not been studied. Thus, the time of floral differentiation in longan trees is not clear, making it difficult to investigate the effects of plant growth regulators or temperature on floral induction. The purpose of the present study is to describe the morphological characteristics of the structure and the development of the longan inflorescence.

\section{Materials and Methods}

ObServations in 2000-01. Ten 7- to 8-year-old longan trees were selected in a commercial orchard in Hang Dong (lat. $18^{\circ} 41^{\prime} \mathrm{N}$, long. $\left.98^{\circ} 55^{\prime} \mathrm{E}\right)$, Chiang Mai, Thailand. Most branches that had developed after harvest in Aug. to Sept. 2000 were quiescent and had several nodes with small, immature leaves on their tips in late Nov. 2000 (Fig. 1). This part corresponds to an apical bud

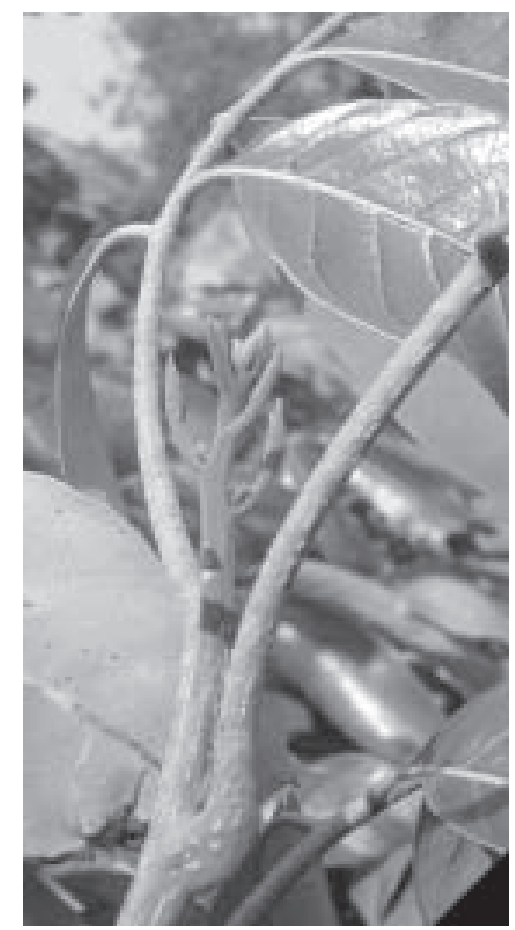

Received for publication 31 Mar. 2005. Accepted for publication 25 June 2005.
Fig. 1. A quiescent terminal shoot of longan. 
in other plants, in respect that it subsequently grows as the next flush. However, it is not covered with scale leaves unlike an apical bud. It has an appearance of the terminal shoot that has just started to grow. Therefore, this part was designated as a terminal shoot in this study whether it was quiescent or growing. For the anatomical study of the development of inflorescence, 20 terminal shoots were collected from five trees at 1-week intervals from 8 Dec. 2000, until 17 Mar. 2001. Samples were fixed in FAA [5 formalin : 5 acetic acid : 90 ethanol (50\%)], dehydrated through a tert-butyl alcohol series, and embedded in paraffin wax. Infiltration of paraffin into quiescent longan shoots was insufficient, so microtome sections were broken or separated from the slide glasses easily. Thus, paraffin blocks were shaved to expose the embedded shoots and soaked in water to moisten the shoots. Longitudinal serial sections were obtained using a microtome at $12 \mu \mathrm{m}$, stained with $0.01 \%$ toluidine blue-O, and observed under a microscope.

From the other five trees, 25 uniform inflorescences were selected at the end of February, 3 weeks after emergence. The number of secondary axes and tertiary axes, and the number of dichasia formed directly on the distal portion of the primary, secondary and tertiary axes were counted before full bloom in mid-Mar. 2001. From these trees, two inflorescences per tree were selected, and 18 dichasia per inflorescence were tagged before anthesis. The number of flowers that opened per dichasium was recorded at 2- to 3-d intervals starting from initial anthesis.

ObSERVATIONS in 2001-02. Fifteen 7- to 8-year-old longan trees were selected in the experimental orchard of Chiang Mai Univ. in Maehia (lat. $18^{\circ} 46^{\prime} \mathrm{N}$, long. $99^{\circ} 05^{\prime} \mathrm{E}$ ), Chiang Mai, on 26 Nov. 2001 with 10 trees used for the measurements of shoot growth and the anatomical observations, and five trees used only for the measurements of shoot growth. For the anatomical study, two terminal shoots from each tree were collected at a 1-week interval, and the long shoots were cut into several fragments. Samples were fixed in FAA, dehydrated, and embedded in paraffin wax as described above. Longitudinal serial sections were obtained using a microtome at $12 \mu \mathrm{m}$, and stained with toluidine blue-O. The number of leaf primordia formed on the main and lateral axes was counted under a microscope. For the measurement of shoot growth, 10 terminal shoots per tree were tagged on 26 Nov. 2001, and shoot length was measured at 1week intervals. The time at which bracts became visible was recorded. Data on 33 terminal shoots that were abscised during the experiment were excluded.

\section{Results}

MoRPHOLOGICAL CHARACTERISTICS OF LONGAN INFLORESCENCE. Longan leaves are paripinnate, and form on the main axis in alternate phyllotaxis at a divergence angle of $144^{\circ}$. The inflorescence has a monopodial main axis (primary axis) and lateral axes that are arranged alternately and indefinitely on the main axis at a divergence angle of $144^{\circ}$ (Fig. 2). The secondary axes at the proximal part of the primary axis are also monopodial, forming the tertiary axes alternately and indefinitely. The tertiary axes on a secondary axis increase in number downwards along the primary axis and are monopodial at the proximal part of the basal secondary axes. In this way, inflorescences have three or four orders of paniculate monopodial axes. Lateral axes at the distal zone of these monopodial axes have terminal flowers (primary flowers), and two axes formed at the base of the peduncles of terminal flowers also have terminal flowers (secondary flowers),

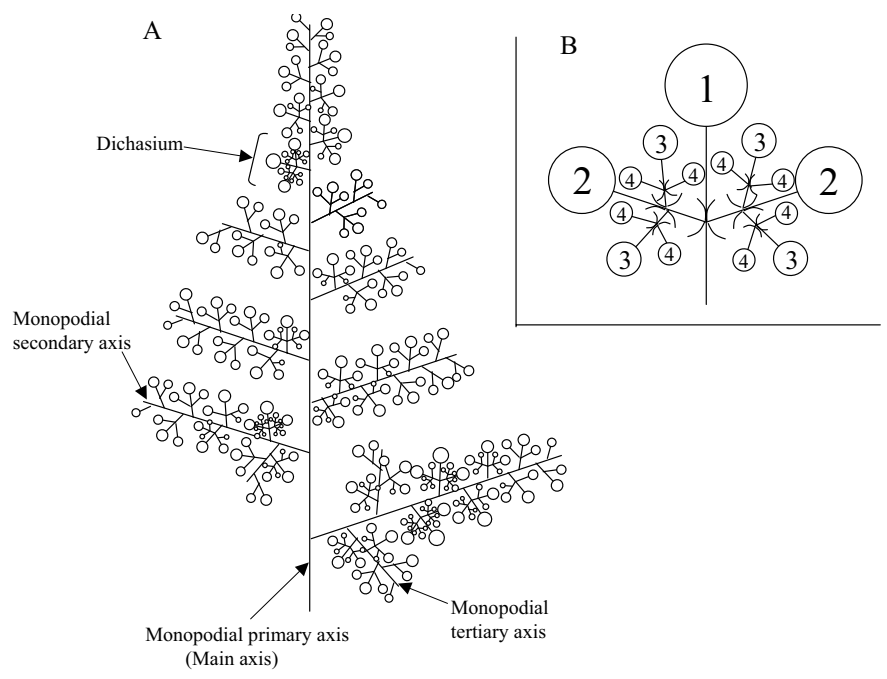

Fig. 2. Diagram of longan inflorescence (A) and dichasium (B). Numbers indicate the primary, secondary, tertiary, and quarternary flowers.

which appear and open later than the primary flowers (Fig. 2B). The serial formation of pairs of new axes resulted in the formation of compound dichasia. The number of pairs of axes within a dichasium increases downwards along the monopodial axes (Fig. 2A). The pairs of the higher orders within a dichasium often lack one of two axes. Monopodial axes of longan inflorescences do not bear terminal flowers.

One to two secondary axes at the base of the primary axes often abort, and the number of remaining monopodial secondary axes per main axis was $14.3 \pm 2.4$ (mean $\pm \mathrm{SD}$ ). The number of monopodial tertiary axes on the longest secondary axis, which is usually located at the base of the primary axis, was $5.4 \pm 1.7$. The number of dichasia formed directly on the distal portion of the monopodial primary, secondary, and tertiary axes were $26.1 \pm 6.3,20.1 \pm 3.7$, and $8.7 \pm 3.0$, respectively, amounting to $567 \pm 44$ per inflorescence. The average number of flowers per dichasium was $6.1 \pm 0.2$.

MORPHOLOGICAL CHANGES OF INFLORESCENCE DURING DEVELOPMENT IN 2001-02. At the end of Nov. 2001, $15.5 \pm 0.3$ leaf primordia had differentiated alternately on the main axes of terminal shoots. The leaf primordia had bulges on the adaxial side. Most leaf primordia, except for two to three at the summit of the shoot apex, had leaflets that would develop the foliage leaves (Fig. 3A), and axillary buds were visible in their axils. In the axillary buds below the sixth node from the summit of main axes, leaf primordia were visible on the secondary axes. These leaf primordia also had bulges on the adaxial side and developed leaflets, except for three prophylls (i.e., scale leaves formed at the basal part of lateral axis) (Fig. 3B). The number of leaf primordia on the secondary axes increased at a rate of one primordium per node as the nodal position of the axillary buds increased along the main axes (Fig. 4). The same relationship was found between the number of leaf primordia on the tertiary axes and their nodal position on the secondary axes (Fig. 4). Some tertiary axes produced quaternary axes with leaf primordia.

On 24 Dec. 2001, two of 20 terminal shoots developed leaf primordia that curved toward an adaxial side and lacked leaflets (Table 1). These leaf primordia were slightly wider than foliage leaf primordia. In axils of the wide and curved primordia, the dichasia differentiated later; thus, it is concluded that these primordia were bract primordia. Bract primordia were observed in one of 20 

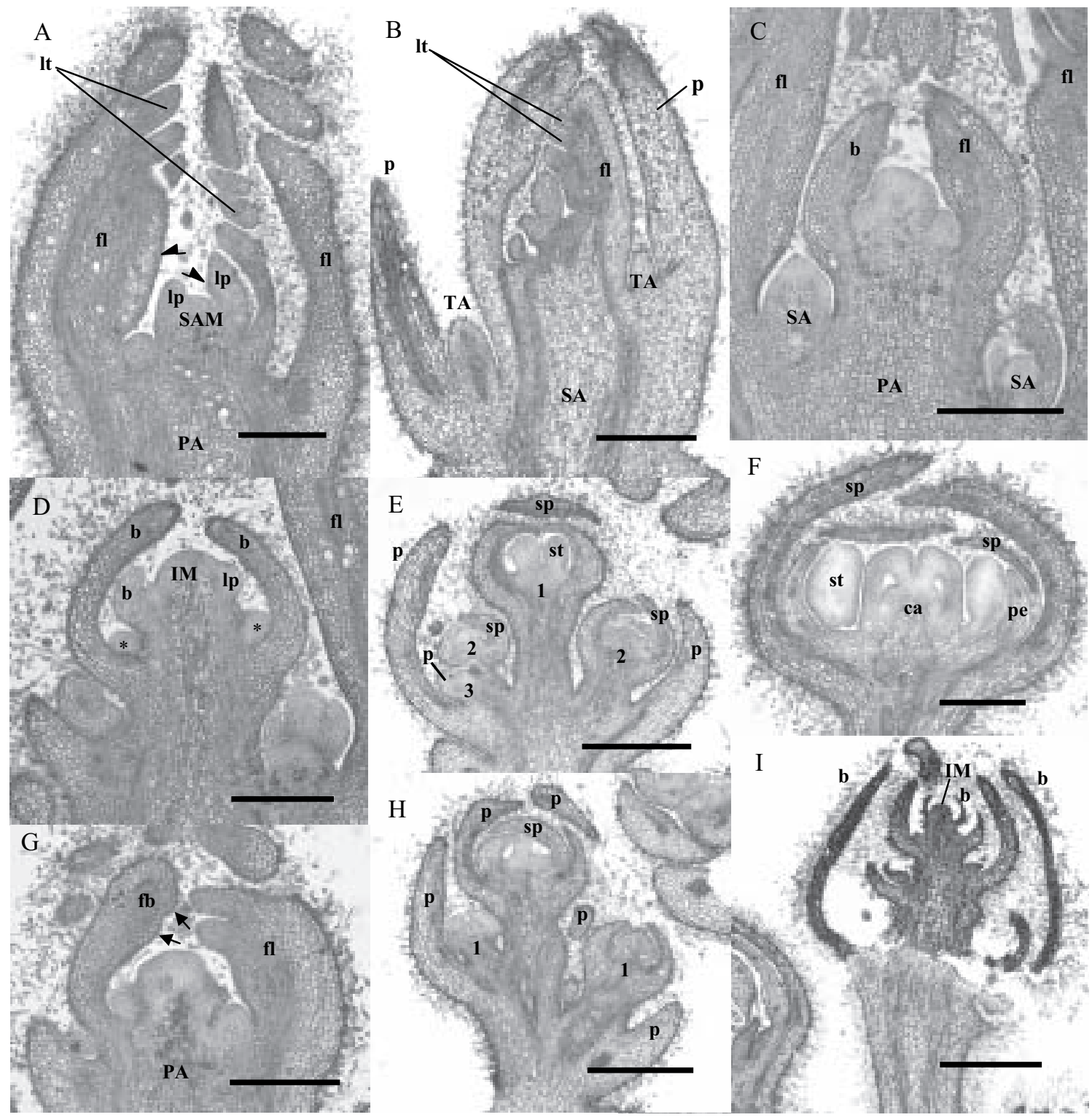

Fig. 3. Microphotograph of terminal shoots of longan. (A) Shoot apex on 26 Nov. 2001. Leaf primordia have bulges on the adaxial side (arrows); bar $=600 \mu \mathrm{m}$. (B) Secondary axis on the terminal shoot on 26 Nov. 2001; bar $=500 \mu \mathrm{m}$. (C) Bracts at early stages of differentiation $(28 \mathrm{Jan} .2002)$; bar $=300 \mu \mathrm{m}$. (D) Bracts at advanced stages of differentiation (28 Jan. 2002). Axillary buds (*) subtended by bract primordia are to develop into dichasia; bar $=300 \mu \mathrm{m}$. (E) Dichasium on 4 Feb. 2002. Prophylls at the base of the peduncles of secondary flowers are not visible in this picture; bar $=500 \mu \mathrm{m}$. (F) Primary flower on 4 Feb. 2002 ; bar $=300 \mu \mathrm{m}$. (G) Transition leaf primordium from foliage leaf to bract (28 Jan. 2002). It slightly curves toward the adaxial side and has a few, small protuberances (arrows); bar $=300 \mu \mathrm{m}$. (H) Lateral axis which forms more than two prophylls alternately and acropetally but ends in a terminal flower (4 Feb. 2002). Dichasia are differentiated in axils of prophylls; bar $=500 \mu \mathrm{m}$. (I) Shoot apex on 2 Mar. 2002. Shoot tip withers and is about to drop; bar $=500 \mu \mathrm{m}$. b. $=$ bract, ca. $=$ carpel, $\mathrm{fl} .=$ foliage leaf primordium, fb. $=$ transition leaf from foliage leaf to bract, $1 \mathrm{p} .=$ leaf primordium, lt. = leaflet. $\mathrm{p} .=$ prophyll, pe. $=$ petal, sp. $=$ sepal, st. $=$ stamen, tf. $=$ terminal flower, IM. $=$ inflorescence meristem, PA. $=$ primary axis, SA. = secondary axis, SAM. $=$ shoot apical meristem, TA.$=$ tertiary axis, $1 .=$ primary flower of dichasium, 2. = secondary flower of dichasium, 3. = tertiary flower of dichasium.

terminal shoots on 31 Dec. and 7 Jan., but not on 14 and 22 Jan. However, on 28 Jan. they were detected in $55 \%$ and $90 \%$ of the terminal shoots of the primary and secondary axes, respectively (Fig. 3C, Table 1). Thereafter, apical meristems formed bract primordia sequentially on the main and lateral axes. When bract primorida were fully developed, they became more curved and the bulges on the adaxial side disappeared (Fig. 3D). In shoots that had formed a certain number of bracts, the newly developed bract primordia were already well curved at emergence, and the shoot apical meristems were broad.

In the axils of bract primordia, two prophylls differentiated on opposite sides of the axes 1 week after the appearance of the bract primordia. Thereafter, apical meristems of the axillary buds formed five sepals, five petals, seven to nine stamens, and one carpel in succession, resulting in the formation of the primary flowers of dichasia (Fig. $3 \mathrm{E}$ and F). When sepal primordia of the primary flower were visible, axillary meristems, which would develop secondary flowers of the dichasia, appeared in the axils of the pair of prophylls and then differentiated new prophylls. Similarly, the tertiary flowers were formed in the axils of the new prophylls. The axillary buds subtended by prophylls at higher orders often aborted.

Some shoots produced leaf primordia with a slight curve and a few, very small protuberances just above the uppermost 


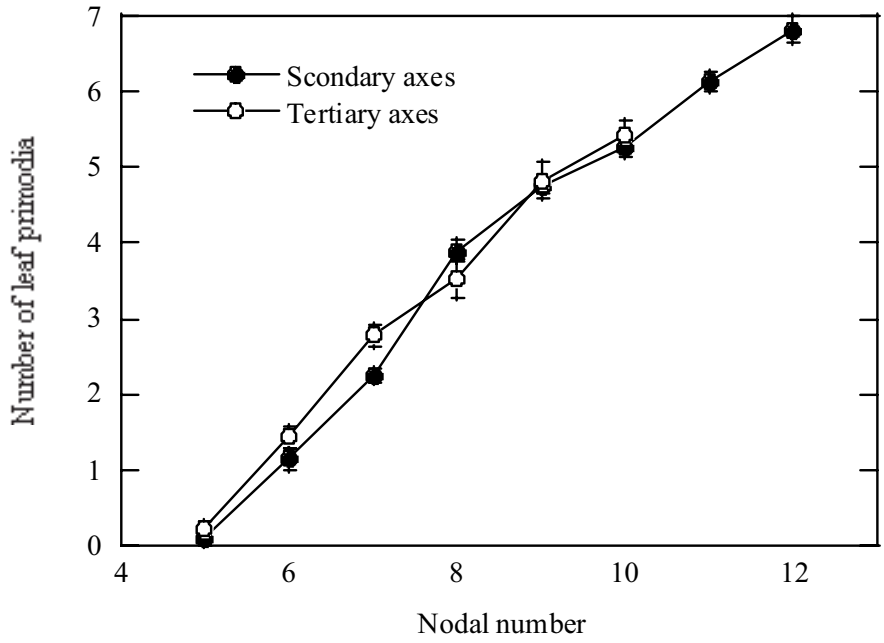

Fig. 4. Relationships between the number of leaf primordia on the secondary and tertiary axes and nodal number of the primary and secondary axes, respectively, on terminal shoots of longan on 26 Nov. 2001.

Table 1. Timing of the emergence of bracts and sepals on terminal shoots of longan

\begin{tabular}{lccc}
\hline Date & $\begin{array}{c}\text { Shoots } \\
\text { examined } \\
\text { (no.) }\end{array}$ & $\begin{array}{c}\text { Shoots with } \\
\text { bracts observed } \\
\text { (no.) }\end{array}$ & $\begin{array}{c}\text { Shoots with } \\
\text { sepals observed } \\
\text { (no.) }\end{array}$ \\
\hline 26 Nov. & 20 & $0^{\mathrm{z}}(0 \mathrm{y})$ & 0 \\
3 Dec. & 19 & $0(0)$ & 0 \\
10 Dec. & 20 & $0(0)$ & 0 \\
17 Dec. & 20 & $0(0)$ & 0 \\
24 Dec. & 20 & $2(2)$ & 0 \\
31 Dec. & 18 & $1(1)$ & 0 \\
7 Jan. & 20 & $1(1)$ & 1 \\
14 Jan. & 20 & $0(0)$ & 0 \\
22 Jan. & 20 & $0(0)$ & 0 \\
28 Jan. & 20 & $11(18)$ & 3 \\
4 Feb. & 20 & $16(17)$ & 13 \\
\hline
\end{tabular}

${ }^{\mathrm{z}}$ Number of shoots in which bracts were visible on the main axes. yNumber of shoots in which bracts were visible on the lateral axes. xNumber of shoots in which sepals were visible in the axils of bracts on the main axes.

foliage leaf primordium before the formation of bract primordia (Fig. 3G). These leaf primordia were also observed on developed inflorescences by naked eye in mid-February. The axillary bud subtended by these leaf primordia formed more than two prophylls alternately and acropetally along the central axis, but finally ended in a terminal flower. In the axils of these prophylls, dichasia were differentiated (Fig. $3 \mathrm{H}$ ). This type of axis was also often observed in the axils of the uppermost foliage leaf and the lowest bract.

Similar microscopic observations of the terminal shoot apices in Winter 2000-01, showed that bracts began to emerge on the main axis starting from 19 Jan., and the shoot apical meristem began to broaden at the same time. One week later, sepal primordia were observed in the axils of bract primordia. Shoot apical meristems gradually became smaller, eventually withered and abscised between late February and mid-March (Fig. 3I).

OBSERVATION OF TERMINAL SHOOT DEVELOPMENT BY NAKED EYE IN WINTER 2001-02. Of 117 terminal shoots, 116 shoots elongated, while $77(65.8 \%)$ formed dichasia on both the main and lateral axes, and eventually developed into inflorescences (Fig. 5A). The inflorescence differentiated 17.2 \pm 2.3 monopodial secondary axes, but approximately two axes on the base usually aborted; thus $15.1 \pm 2.1$ monopodial secondary axes remained. On the longest secondary axis, which was usually located near the base of the primary axis, $8.3 \pm 2.4$ monopodial tertiary axes existed. Of 117 terminal shoots, 16 shoots (13.7\%) developed no lateral axes on either the proximal or distal part, and developed into vegetative shoots (Fig. 5B). The remaining 23 shoots (19.7\%) developed a small number of short monopodial lateral axes and formed dichasia only on lateral axes, not directly on the main axes (Fig. 5C).

Some terminal shoots began to elongate in mid-January, while most began to elongate at the end of January. The appearance of bracts on the lateral axes (i.e., the first sign of inflorescence formation) could be detected by the naked eye on $4 \mathrm{Feb}$. One to 2 weeks later, the bracts became visible on the main axis. The first flowers opened in mid-March.

\section{Discussion}

INFLORESCENCE STRUCTURE. The longan inflorescence has three or four orders of monopodial axes, with the higher-order axes forming on the proximal part of the lower-order axes (Fig. 2A). If single flowers form on a distal part of each of these monopodial axes, the inflorescence is defined as panicle. In inflorescence of longan, however, dichasia are formed on the distal parts of monopodial axes (Fig. $2 \mathrm{~A}$ and B). This type of inflorescence, in which cymose partial inflorescences, including dichasia, are arranged on monopodial axes, is called thyrse (Barfod, 1988; Bell, 1991; Weberling, 1992). If thyrse forms two orders or more than two orders of monopodial axes, it is termed as double thyrse or pleiothyrse, respectively (Barfod, 1988; Weberling, 1992). Thus, the longan inflorescence is classified as pleiothyrse. Yaacob and Subhadrabandhu (1995) reported that the longan inflorescence is composed of dichasia, but how the inflorescence is constructed with dichasia was not mentioned. They also described that a dichasium consists of three flowers in longan, and that only one flower develops; however, the results show that longan inflorescences develop compound dichasia and the degree of branching within a dichasium increases downwards along the monopodial axes, as is found in plant species with thyrse (Weberling, 1992). In some cases, compound dichasia at the base of monopodial axes develop quaternary flowers. It has been shown that the litchi inflorescence is composed of compound dichasia with quaternary flowers in highly branched inflorescences (Robbertse et al., 1995). Robbertse et al. (1995) also reported that the litchi inflorescence is pleiothyrsoid (i.e., a pleiothyrse that forms a terminal flower). On the contrary, the apical meristems of monopodial axes of the longan inflorescence reduce in size with time, whether the axes are main or lateral, and finally abscise without the formation of the terminal flower (Fig. 3I). In addition, the longan inflorescence shows a different phyllotaxis from the litchi inflorescence [i.e., alternate phyllotaxis at divergence angle of 2/5 in longan, but decussate phyllotaxis in litchi (Robbertse et al., 1995)].

INFLORESCENCE DEVELOPMENT. When the vegetative flush of growth ceased, longan trees had very short shoots with several immature leaves on the tips of branches. It is considered that floral induction occurs under cool winter conditions in longan, and the short terminal shoots develop into the large and complex inflorescences at subsequent warm temperature (Davenport and Stern, 2005; Nakasone and Paull, 1998). In northern Thailand, the cool season starts in late November to early December and ends in late January to early February. At the end of November, 

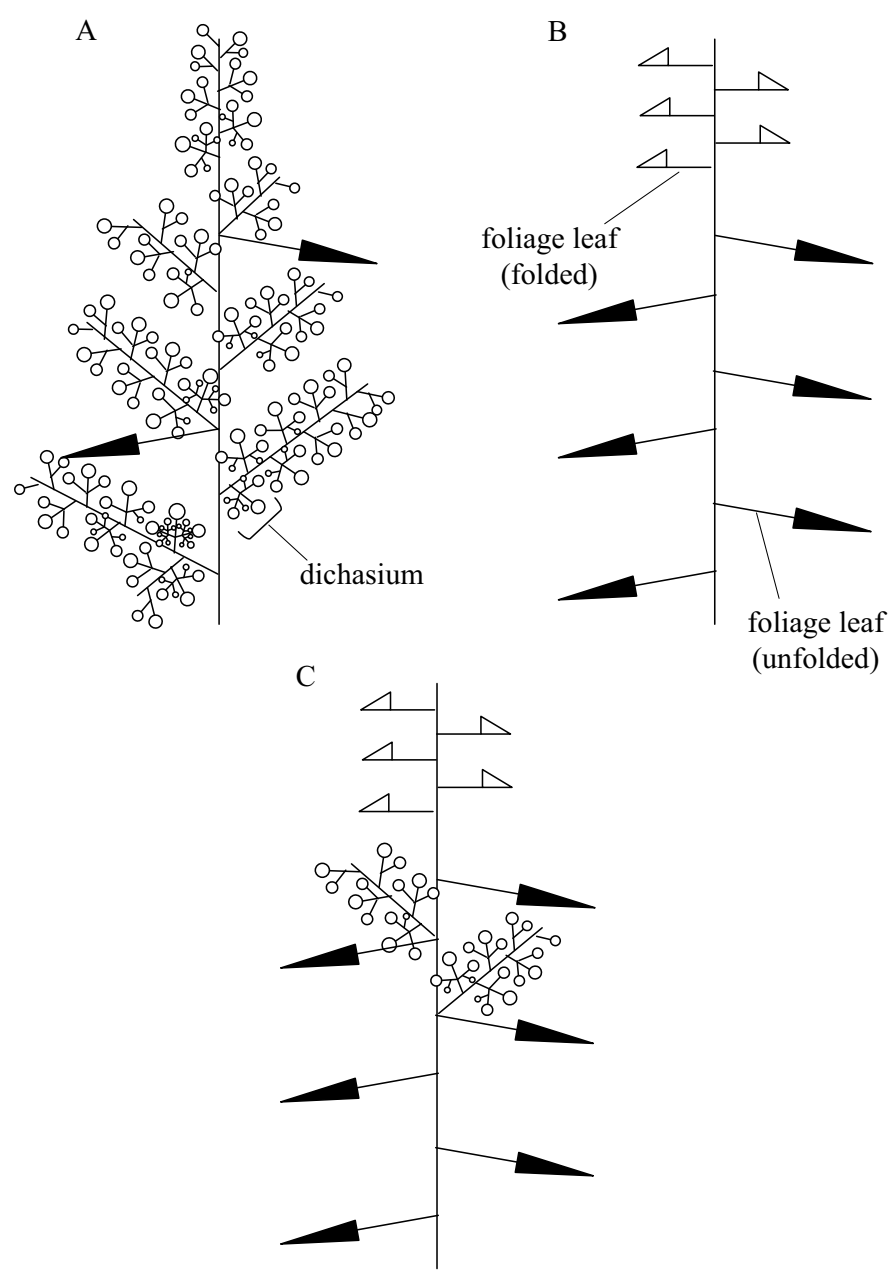

Fig. 5. Diagrams of three types of longan shoots: (A) inflorescence, $(\mathbf{B})$ vegetative shoot, and (C) shoot of intermediate type. Arrows with full arrowheads and with half arrowheads indicate folded and unfolded foliage leaves, respectively.

the terminal shoots of longan consisted of two to three orders of monopodial lateral axes subtended by foliage leaf primordia and prophyll primordia. There were 15.5 foliage leaves on the primary axis. The relationship between the number of leaf primordia within axillary buds and the nodal position of the axillary buds indicates that the number of leaf primordia on the secondary axes was smaller by five than the node number on the primary axes; if the terminal shoots had 15.5 leaf primordia on the primary axes, the basal axillary buds had differentiated 10.5 of leaf primordia or initials of tertiary axes (Fig. 4). Because the basal two secondary axes usually aborted, the number of initials that would develop into mature monopodial secondary axes was 13.5. The corresponding value for the monopodial tertiary axes on the basal secondary axes was estimated to be 8.5. These values were close to the final number of axes in inflorescences in March (15.1 and 8.3, respectively). Thus, it is suggested that most of the initial monopodial lateral axes had differentiated in the axils of foliage leaf primordia or prophyll primordia at the end of November.

When the cool season terminated at the end of January, the apical meristem of each preformed monopodial axis began to form bract primordia instead of foliage leaf primordia alternately and indefinitely, and gave rise to new axes in axils of bract primordia (Table 1). These new axes, however, ended in terminal flowers (primary flowers) immediately after they produced pairs of pro- phylls (Fig. 3E). Two new sympodial axes emerged in the axils of a pair of prophylls and produced two pairs of prophylls and two secondary flowers. The formation of terminal flowers and the emergence of new sympodial axes in the axils of prophylls were repeated, resulting in the formation of compound dichasia (Fig. 3E). These results indicate that apical meristems of all the axes produce foliage leaf primordia and monopodial axes sequentially during vegetative growth, but produce bract primordia and sympodial axes during reproductive growth; however, the transition from vegetative to reproductive growth does not change the developmental pattern of the axes that had developed before transition. They continued monopodial growth after transition, resulting in the formation of the inflorescence without a terminal flower. Qiu et al. (2001) observed morphological changes near the apices of terminal shoots of longan at floral induction and described that the first sign of inflorescence formation is the appearance of bracts on the lateral axes, followed by the appearance of bracts on the main axis of the terminal shoots. Other studies showed that longan inflorescence consists of dichasia (Subhadrabandhu, 1990; Yaacob and Subhadrabadhu, 1995); however, changes on the whole terminal shoot, including the emergence of sympodial developmental patterns on the monopodial secondary and tertiary axes as well as on the primary axes, at the appearance of bract primordia, have not been demonstrated. In other species with thyrse or thyrsoid, such as litchi and mango (Mangifera indica L.), it has also not been demonstrated how the monopodial and sympodial axes are formed on terminal shoots (Barfod, 1988; K. Ishihata, personal communication; Shukla and Bajpai, 1974). Thus, this study is the first to demonstrate the changes in the developmental patterns on the whole terminal shoot in floral induction of plants with thyrse or thyrsoid.

In late December, leaf primordia with a few, small protuberances became visible above the uppermost usual foliage leaf primordia on the main axes (Fig. 3G). These protuberances are apparently rudiments of leaflets. It is likely that these leaf primordia were transition leaves from foliage leaves to bracts because they occurred between the uppermost foliage leaf and the first bract on the main axis and showed an intermediate morphology. Many of the axes subtended by the transition leaves developed as monopodial axes at first (more than two prophylls were differentiated alternately and acropetally along these axes), but later developed as sympodial axes (they formed terminal flowers and gave rise to dichasia in axils of prophylls) (Fig. 3H). Therefore, it is likely that these axes are at the transition from monopodial to sympodial axes.

There were also intermediate shoots that produced dichasia on several lateral axes, but not on the main axes (Fig. 5C). Because bracts appeared slightly earlier on the lateral axes than on the main axes (Table 1), it is possible that these shoots were exposed to conditions unfavorable for flower induction immediately after the apical meristems of lateral axes, but not main axes, were flower-induced. Davenport and co-workers (Davenport and Nunez-Elisea, 1997; Davenport and Stern, 2005; Nunez-Elisea and Davenport, 1994; Nunez-Elisea et al., 1996) reported that intermediate shoots are produced in mango when buds are exposed to cool temperatures, followed by warm temperature conditions (i.e., conditions unfavorable for mango floral induction). They considered that the shoot apical meristems had not been induced to flower when trees were transferred to warm temperatures and, as a result, shoot apical meristems continued to produce leaf initials, similar to vegetative shoots, although axillary meristems initiated inflorescence morphogenesis (Nunez-Elisea et al., 1996). 
The timing of the emergence of inflorescence has often been determined by naked eye in studies of the effects of temperature or plant growth regulators on litchi floral induction (Menzel et al., 1989; Menzel and Simpson, 1991, 1995; Qiu et al., 2001; Subhadrabandhu and Yapwattanaphun, 2001); however, the determination of the timing of inflorescence emergence by naked eye is arbitrary. In this experiment, we found that the sepals of the secondary or tertiary flowers within dichasia were observed under a microscope when bracts became visible by naked eye on the lateral axes. This was one week later than the microscopic appearance of bracts on the lateral axes (Table 1). This knowledge will be useful for obtaining a better understanding of longan floral induction in relation to factors such as temperature and plant growth regulators.

\section{Literatre Cited}

Barfod,A. 1988. Inflorescence morphology of some South American Anacardiaceae and possible phylogenetic trends. Nordic J. Bot. 8:3-11.

Bell, A.D. 1991. Plant form: An illustrated guide to flowering plant morphology. Oxford Univ. Press, Oxford.

Davenport, T.L. and R. Nunez-Elisea. 1997. Reproductive physiology, p. 69-146. In: R.E. Litz (ed.). The mango: Botany, production and uses. CABI, Wallingford, Oxon, U.K.

Davenport, T.L. and R.A. Stern. 2005. Flowering, p. 87-113. In: C.M. Menzel and G.K. Waite (eds.). Litchi and longan: Botany, cultivation and uses. CABI, Wallingford, Oxon, U.K.

Menzel, C.M., T.S. Rasmusen, and D.R. Simpson. 1989. Effects of temperature and leaf water stress on growth and flowering of litchi (Litchi chinensis Sonn.). J. Hort. Sci. 64:739-752.
Menzel, C.M. and D.R. Simpson. 1991. Effects of temperature and leaf water stress on panicle and flower development of litchi (Litchi chinensis Sonn.). J. Hort. Sci. 66:335-344.

Menzel, C.M. and D.R. Simpson. 1995. Temperatures above $20^{\circ}$ reduce flowering in lychee (Litchi chinensis Sonn.). J. Hort. Sci. 70:981-987.

Nakasone, H.Y. and R.E. Paull. 1998. Tropical fruits. CABI, Oxon, U.K.

Nunez-Elisea, R. and T.L. Davenport. 1994. Flowering of mango trees in containers as influenced by seasonal temperature and water stress. Sci. Hort. 58:57-66.

Nunez-Elisea, R., T.L. Davenport and M.L. Caldeira. 1996. Control of bud morphogenesis in mango (Mangifera indica L.) by girdling, defoliation and temperature modification. J. Hort. Sci. 71:25-39.

Qiu, J., X. Luo, and D. Wu. 2001. Regulation of flower bud differentiation in longan. Acta Hort. 558:225-228.

Robbertse, H., J. Fivaz, and C. Menzel. 1995. A reevaluation of tree model, inflorescence morphology, and sex ratio in lychee (Litchi chinensis Sonn.). J. Amer. Soc. Hort. Sci. 120:914-920.

Shukla, R.K. and P.N. Bajpai. 1974. Blossom bud differentiation and ontogeny in litchi (Litchi chinensis Sonn.). Indian J. Hort. 31:226-228.

Subhadrabandhu, S. 1990. Lychee and longan cultivation in Thailand. Rumthai Publ., Bangkok, Thailand.

Subhadrabandhu, S. and C. Yapwattanaphun. 2001. Regulation of offseason flowering of longan in Thailand. Acta Hort. 558:193-198.

Thunyarpar, T. 1998. Physiological aspects on flowering of lychee and longan. J. Jpn. Soc. Hort. Soc. 67:1161-1163.

Yaacob, O. and S. Subhadrabandhu. 1995. The production of economic fruits in south-east Asia. Oxford Univ. Press, Kuala Lumpur, Malaysia.

Weberling., F. 1992. Morphology of flowers and inflorescences. Cambridge Univ. Press, London, U.K. 